Uhle and Mackinney: Comparative Results of the Wassermann Test. Journal A. M. A., Sept. 4, 1915, p. 863.

Test. N. Y. Med. Journal., Feb. 22, 1913.

so Craig: Interpretation of the Wassermann Test. Jour. Am. Med. Sc., January, 1916 , p. 41.

"Schmitt, A.:" Die Salvarsantodesfalle, und ihre Ur'sachen mit Berilcksichtigung der Salvarsanschaden. Munch. mediz. Woch., June 16, 1914, No. 64 , p. 1339 .

\section{A REVIEW OF 127 CLINICAL CASES OF ATAXIC PARAPLEGIA.*}

By G. H. Bigelow, Boston.

[From the Neurological Clinic, Massachusetts General Hospital.]

From 1903 to November, 1915, the out-patient records at the Massachusetts General Hospital show that the diagnosis "ataxic paraplegia" has been made 127 times. Of these, $70 \%$ were males, whereas in the whole Out Patient Department, approximately $58 \%$ are males.

In 83 cases we established a possible etiology, though some, perhaps, on rather meagre evidence. They were: syphilis 43 , following accident 10, following acute infections 6 (diarrhea, grippe, rheumatic fever, typhoid, infectious arthritis, and meningitis), hemiplegia 5 (which suggested hypertension with possible hemorrhage, etc.), alcoholism 5, malformations or irregularities of the spine 3 , hypertension (at time of examination) 3 , chronic disease 2 (gout and sepsis), exhaustion 2, anemia, lead poisoning, neurotic family history, exposure, heredity, tumor and pellagra, each one. In 44 cases no possible etiology could be found.

Of the 43 syphilitic cases only 7 showed positive laboratory findings in the blood ( 3 cases), or spinal fluid ( 2 cases), or both ( 2 cases). Two were strongly positive, one moderately, and one weakly positive, while three were reported "positive" without any qualification. One case was considered positive in spite of negative laboratory findings because of the marked improvement with salvarsan. Eight gave a history of syphilis; 6 showed it clinically, that is, there were scars and pupils; 18 were syphilitic clinically and also by history; while 2 showed it clinically and therapeutically, i.e. improved under anti-specific treatment. One was diagnosed in the House, spinal syphilis in spite of negative laboratory findings on the basis of symptoms and irregular pupils. Thus it would seem that syphilis as an etiological factor in ataxic paraplegia is, of course, far less constant than in tabes, and when present is less frank, giving moderately positive or negative laboratory findings.

This is quite contrary to the statements in the literature. Gowers ${ }^{1}$ says, "A history of syphilis is as rare in ataxic paraplegia as it is common in locomotor ataxia." Dana ${ }^{2}$ agrees with this. Osler ${ }^{3}$ denies the relationship to syphilis except in rare instances. Putnam ${ }^{4}$ finds the indications

* Read at a meeting of the Boylston Medjcal Society, Feb. 4, 1010 . of syphilis exceedingly rare, if not wholly absent.

Here is the history in brief of one of the typical cases:

William S., age 36 , seen first in October, 1903, complaining of weakness of the legs, of insidious onset, which the patient dates from a fall on the ice six years before. Feet feel as if walking on felt. Difficulty in walking in the dark. Severe frontal headaches for the past two months. Physical examination shows impaired muscle sense, otherwise negative. A year later unequal and irregular pupils were noted. In 1910 examinations showed increased knee-jerks, positive Babinski and clonus, urinary incontinence and a spastic gait. Dr. Baldwin notes that it is a typical case of spastic paraplegia. In 1914 two blood Wassermanns were done and both were positive. Last November besides the signs mentioned above, he showed a positive Romberg. His ataxia was so great that he was forced to use crutches. There was subjective numbness as high as the crests of the ilia. Pain and temperature sense were normal, but light touch was impaired. The urinary incontinence had improved. His arms were unaffected. Before the days of the Wassermann this case would without doubt have been considered of traumatic origin.

The complaints given at the first visit were tabulated. Of the 127 cases, 112 or $88.3 \%$ complained of objective or subjective disturbances of the legs. Of the other $11.7 \%$, the primary complaint was in some cases urinary disturbances, in others paresthesia or weakness of the arms, dizziness, headache, etc. It is because of this preponderance of leg complaints, undoubtedly, that $50 \%$ of the cases not admitted directly to the Nerve Room, were sent to the Orthopedic. The predominant symptoms were also tabulated. Those showing principally spasticity were 52 , ataxia 49 , paresthesia 9 , bladder symptoms 3 , flaccidity 3 . In 11 cases the notes were so meagre that it was impossible to determine.

The treatment was enormously varied. It included mercury, salvarsan, K I, Zander, electricity, massage, Fowler's solution, iron, brace, jacket, Thomas heel, advice, urotropin, and "stop lead." In each case the etiological factor, when discovered, was attacked; otherwise the treatment was symptomatic.

As to the course of the disease, only 71 cases returned often enough for any conclusions to be drawn. Of these 25 were better, 18 were worse, and 27 practically stationary. One patient was entirely cured, according to the record, but the notes are so meagre that the diagnosis may well be questioned.

In conclusion it seems from the analysis of these cases that syphilis is an important etiological factor in ataxic paraplegia.

\section{REPERENCES.}

1 Gowers: Inancet 1886 , Vol i p.

2 Dana: Jour, of Nervous and Mental Diseases, 1890, Vol. xxvi, p. ${ }^{1}$ Osl - Putnam and Taylor: Jour. of Nervous and Mental Discases, 1901, Vol xxvii, p. 1. 